\title{
ESTRATÉGIA DE NEGÓCIO VERSUS ESTRATÉGIA DE RECURSOS HUMANOS: AS INFLUENCIAS DO FUNDADOR NAS PEQUENAS EMPRESAS
}

\section{BUSINESS STRATEGY VERSUS HUMAN RESOURCES STRATEGY: THE INFLUENCE OF THE FOUNDER IN SMALL BUSINESS}

\author{
Recebido: 09/09/2016 - Aprovado: 18/10/2016 - Publicado: 10/12/2016 \\ Processo de Avaliação: Double Blind Review
}

\author{
Luciana Campos Lima ${ }^{1}$ \\ Doutora em Administração FEA/USP \\ Fundação Escola de Comércio Álvares Penteado-FECAP \\ lucamposlima@hotmail.com \\ Juliana Popp Barbosa Lima \\ Graduada em Biblioteconomia e ciência da informação \\ Universidade Federal de São Carlos-UFSCAR \\ juliana.popp@yahoo.com.br
}

\section{RESUMO}

As empresas de pequeno e médio porte com caráter familiar tem sido objeto de estudos nos últimos anos, especialmente sobre o tema sucessão, por ser um processo extremamente crítico para a longevidade e sustentabilidade da organização. No entanto, a figura do fundador e seu impacto nessas organizações é pouco explorada no meio acadêmico. Assim, esse artigo busca suprir essa lacuna, abordando as influências do fundador na disseminação das estratégias de negócio e de Recursos Humanos (RH) nessas empresas. Através de uma pesquisa de caráter qualitativo e quantitativo, foi realizado um estudo de caso de uma única organização buscando uma análise mais aprofundada do tema. A coleta de dados qualitativa deu-se por meio de uma entrevista com roteiro semiestruturado com o fundador da organização e a qualitativa por meio de aplicação de um questionário com perguntas fechadas com funcionários de diversos níveis hierárquicos. Foi possível observar que os valores e princípios

\footnotetext{
${ }^{1}$ Autor para correspondência:, Fundação Escola De Comércio Álvares Penteado- FECAP, Av Liberdade, 532, Liberdade, São Paulo, SP, Brasil, 01502-001.
} 
pessoais do fundador estão permeados na organização, refletidos na missão e valores da empresa, assim como a forma como o fundador trata temas como estratégia de negócio e o papel da gestão de pessoas, o que tem sido determinante para a inclusão e condução desses tópicos dentro de organizações de cunho familiar. O objetivo de analisar a disseminação das estratégias de negócio e a de Recursos Humanos pelo Fundador foi alcançado.

Constatou-se que, de forma geral, as estratégias retratam a maneira de ser do Fundador, entretanto, a disseminação dessas, para os diversos níveis hierárquicos, demonstra uma complexidade maior, como no caso da GRH.

Palavras-chave: fundador, estratégia de negócio, gestão estratégica de recursos humanos, média empresa.

\section{ABSTRACT}

Small and medium-sized businesses with familiar characteristics have been object of study in recent years, especially about the succession process, considering it is extremely critical to the longevity and sustainability of the organization. However, the figure of the founder and its impact in these organizations is less explored in academia. Thus, this article seeks to fill this gap, addressing the influences of the founder in the dissemination of business and HR strategies in these companies. Through a qualitative and quantitative research, there was a case of a single organization study seeking further analysis of the subject. The collection of qualitative data was given through an interview with semi-structured interview with the founder of the organization and the qualitative by applying a questionnaire with closed questions with officials of various hierarchical levels. It was observed that the personal values and the founding principles are permeated the organization, reflected in the mission and values of the company, as well as how the founder treats topics such as business strategy and the role of people management are decisive for inclusion and driving these topics within family-based organizations. The purpose of analyzing the spread of business strategies and human resources of the Founder has been reached. It was found that, in general, strategies portray the way of the Founder, however, the spread of these to the various hierarchical levels, demonstrates a more complex, as in the HRM. 
Key words: founder, business strategy, human resources strategic management, medium-sized business

\section{INTRODUÇÃO}

Segundo Lethbridge (1997), mais da metade dos empregos gerados no mundo são derivados das empresas chamadas familiares. No Brasil, segundo Freitas e Barth (2012), 60\% dos empregos são gerados nessas instituições. Com sua grande participação e influência na economia mundial, o estudo sobre esse tipo de organização é vasto e comum.

No entanto, a literatura sobre empresa familiar está concentrada principalmente na definição do conceito do que caracteriza esse tipo de organização e na questão da sucessão, devido a sua importância para a sustentabilidade da empresa através das gerações.

Poucos estudos estão pautados nos reflexos do estilo do fundador-dirigente dessas organizações na gestão estratégica da empresa e na gestão das políticas de recursos humanos. Dessa forma, o objetivo desse estudo é analisar se existe diferença entre a influência da disseminação estratégica de negócio e a de RH por parte do fundador.

Esse trabalho apresenta um referencial teórico que aborda as características do fundador da empresa familiar, sua relação com o planejamento estratégico e com a área de recursos humanos. Na sequência, é apresentada a empresa objeto desse estudo de caso e os resultados da pesquisa realizada. Finaliza o trabalho com as considerações finais sobre o tema.

\section{REFERENCIAL TEÓRICO}

\subsection{A gestão das pequenas e médias empresas familiares}

Grande parte das empresas de pequeno e médio porte é caracterizada como empresa familiar (LUCAS e FRANCO, 2014). A literatura oferece diversos conceitos do que é uma empresa para ser considerada familiar. Para esse estudo, adotaremos o conceito de Casillas, 
Vázquez e Dias (2007), onde a empresa é denominada familiar quando a família realiza a gestão do negócio, os valores familiares norteiam a organização e a questão da sucessão está diretamente ligada à família.

Lucas e Franco (2014) apontam que nesse tipo de organização existe o conflito dos papéis de proprietários com o de gestores, o que afeta diretamente a gestão do negócio, dada a falta da cultura do planejamento estratégico e de acompanhamento de resultados que não os financeiros. Lucas (2013) ainda aponta que quando os objetivos da família não condizem com os objetivos da organização, tal fato gera disputas pessoais que influenciam no resultado e futuro da organização.

Por outro lado, os valores familiares são refletidos nos valores da organização e isso pode ser usado como uma vantagem competitiva no negócio, por serem valores exclusivos de cada organização (LUCAS e FRANCO, 2014).

A gestão da empresa familiar em sua primeira geração é totalmente pautada pela influência de seu fundador e proprietário (LUCAS, 2013).

\subsection{A influência do Fundador na disseminação das estratégias do negócio}

Para conhecer uma empresa faz-se necessário compreender sua história, sua cultura, ou em outras palavras, acessar os valores de seu fundador (PAPA E LUZ, 2008). Isso porque, o fundador, além de ser o proprietário, também é o principal dirigente da empresa "sendo a cultura organizacional um reflexo dos seus valores e crenças” (FERREIRA et al, 2006, p.1).

Apesar das diversas definições atribuídas a cultura organizacional, ainda tem-se como referência seminal o conceito de Schein (1992) em que cultura organizacional constituiu-se por pressupostos básicos que os indivíduos desenvolvem para lidar com os problemas de integração interna e adaptação externa. Portanto, tais pressupostos são repassados aos demais membros como a maneira correta de se perceber, se pensar e sentir-se na organização. 
Fleury e Fleury (1997) destacam que todos os elementos da cultura organizacional estão diretamente ligados ao fundador da organização. O fundador, através de seu espírito empreendedor, coloca uma ideia sobre um produto ou serviço em prática, originando um negócio que será norteado por seus valores, seu conhecimento e suas crenças, desde a sua fundação até o processo de sucessão (LOURENÇO e FERREIRA, 2012). Ele ainda define e imprime na organização sua visão sobre o mundo e sobre o papel que a empresa deve desempenhar. A Tabela 1 demonstra o que se considerou para este estudo como elementos constituintes da cultura organizacional, no caso, criada e difundida pelo fundador.

Tabela 1 - Elementos da cultura organizacional

\begin{tabular}{|l|l|}
\hline ELEMENTOS & \multicolumn{1}{c|}{ DESCRIÇÃO } \\
\hline Valores & $\begin{array}{l}\text { Hipóteses, premissas e modelos de negócios, que definem o que é } \\
\text { melhor para o negócio e como agir }\end{array}$ \\
\hline Crenças & Forma como são manifestadas as crenças e práticas \\
\hline $\begin{array}{l}\text { Hitos } \\
\text { Mitos }\end{array}$ & $\begin{array}{l}\text { Histórias - Baseada em eventos ocorridos onde os comportamentos da } \\
\text { organização foram reforçados } \\
\text { Mitos - São histórias, mas não baseadas por fatos, que servem para } \\
\text { consolidar os valores da organização }\end{array}$ \\
\hline Tabu & $\begin{array}{l}\text { Orienta o comportamento da organização onde delimita-se o que é } \\
\text { proibido }\end{array}$ \\
\hline Heróis & $\begin{array}{l}\text { O elemento que serve de exemplo aos demais por persistência e } \\
\text { coragem em suas ações }\end{array}$ \\
\hline Normas & $\begin{array}{l}\text { Determinam quem pode e quem não pode tomar decisões e realizar } \\
\text { tarefas }\end{array}$ \\
\hline Comunicação & \begin{tabular}{l} 
Processo ligado às pessoas para a formação da cultura \\
\hline
\end{tabular}
\end{tabular}

Freitas, A. D. (1997). Traços brasileiros para uma análise organizacional. Cultura organizacional e cultura brasileira. São Paulo: Atlas, 38-54.

Os valores básicos da organização são baseados na maneira como o grupo a criou e a desenvolveu, através de características próprias sobre como lidar com os problemas internos e externos (FLEURY E FLEURY, 1997). A cultura, não apenas define um padrão de 
comportamento, como também é usada como controle da organização e base das tomadas de decisões, uma vez que define condutas e controla o ambiente interno, eliminando a possibilidade de contestação de seus paradigmas, ao mesmo tempo em que sofre influências do ambiente externo, o que leva à necessidade de mudanças contínuas em suas premissas, para se adaptar às novas demandas (FREITAS, 1991).

A cultura organizacional da empresa familiar tem algumas características próprias, tais como supervalorização das relações pessoais em detrimento às competências, especialmente nos cargos de gestão que ficam no âmbito familiar, o que prejudica a mudança do comportamento da organização (PAPA E LUZ, 2008). Esse perfil organizacional é decorrente das características peculiares ao fundador, tais como gerenciamento baseado em intuição, visão clara dos seus objetivos e uma postura centralizada e arbitrária, que norteiam a identidade organizacional, sendo seguida por todos os colaboradores (TEIXEIRA, 1984).

A cultura organizacional influencia diretamente na estratégia da organização. Mintzberg (2006) destaca alguns pontos onde essa influência acontece: estilo de tomada de decisões; resistências e superação a essas resistências sobre as mudanças estratégicas; valores dominantes; e choque de cultura.

\subsection{Estratégia de negócio e de recursos humanos}

A definição do conceito da estratégia de negócio vem evoluindo por meio da influência dos cenários econômicos e sociais (PEREIRA E AGAPITO, 2006). Nesse sentido, Porter (1980) aponta que a elaboração da estratégia necessita de uma profunda análise do ambiente no qual a empresa está inserida. Para isso, sugere a investigação de cinco forças competitivas, que são: as ameaças de novos entrantes, o poder de barganha dos fornecedores, o poder de barganha dos clientes, os produtos substitutos e a concorrência. Portanto, a estratégia de uma empresa origina-se a partir da compreensão da estrutura de mercado e produtos.

Contudo, autores como Prahalad e Hamel (1990) propõe uma abordagem divergente a citada, ou seja, a estratégia define-se por meio das competências essenciais da organização. Com raízes na Visão Baseada em Recursos (PENROSE, 1959), essa forma de concepção estratégica destaca a trajetória histórica da empresa, sua teia social, sua maneira única de 
organizar o trabalho e produzir resultados. Logo, nesse caso, a vantagem competitiva resulta em competências únicas, raras e de difícil imitação.

A abordagem que sustenta o desenho estratégico do negócio, sua formalização como um procedimento, ou seja, sua formulação e implantação nas organizações é conhecida como planejamento estratégico (Mintzberg, Ahlstrand e Lampel, 2000). Nesse processo, são definidas metas, missões, objetivos e políticas que irão compor a estratégia (CONTADOR, 1995).

Uma das ferramentas utilizadas para auxiliar na implantação do planejamento estratégico nas organizações é o mapa estratégico, onde segundo Kaplan e Norton (2000) a estratégia é descrita sob a ótica da relação de causa e efeito para o alcance de resultados tangíveis e mensurados através de indicadores de desempenho. Com essa ferramenta é possível definir quais competências e habilidades cada colaborador precisa ter para alcançar os objetivos da organização.

O uso desse tipo de ferramenta permite auxiliar a organização a ter uma gestão estratégica de recursos humanos (GERH). Quando a demanda da área de RH é focada nas necessidades das pessoas e da organização a curto e médio prazo, a área é considerada estratégica, agregando valor ao negócio (ULRICH, 2006). A GERH também diz respeito à atuação direta do RH na tomada de decisão em alto nível estratégico e participação na elaboração da estratégia de negócio que norteia o desenvolvimento de todas as políticas e práticas de gestão de pessoas da organização (BREWSTER, 1994).

Como característica da GERH podemos destacar a análise dos impactos do ambiente externo na organização, objetivos a longo prazo e integração dos objetivos da estratégia da organização com a estratégia de cada área (STOREY, 2007). Nas organizações de caráter familiar, a GERH sofre grande influência do fundador e, em muitos casos, a área é dirigida por esse elemento dentro da organização (LIMA, 2010). Isso acaba acarretando um grau de informalidade elevado e processos não estruturados (RAVAGLIA, 2012).

Huallem (2012) aponta que a forma de relacionamento entre o fundador e seus colaboradores, pela proximidade e informalidade nas relações, impactam diretamente na 
subjetividade adotada na política de gestão de recursos humanos e reflete na análise de competências e habilidades, afetando diretamente a meritocracia.

A área de recursos humanos nas pequenas e médias empresas, como é o caso da empresa objeto do nosso estudo, apresenta algumas características diferenciadas em relação às empresas de grande porte, como não utilizar a estratégia de negócio na elaboração de suas políticas e práticas, que por sua vez são dotadas de alto grau de informalidade, priorização ao controle e monitoramento dos funcionários e falta de investimento na qualificação de mão de obra especializada devido aos altos custos (MAYSON E BARRETT, 2006).

Essas políticas e práticas refletem a gestão do trabalho e a gestão das pessoas para fazer o trabalho, como o processo de contratação, a forma como disciplina e controla sua mão de obra e gerencia as mudanças dos processos de trabalho (BOXALL E PURCELL, 2011). Como isso torna aparente, a gestão do trabalho e das pessoas inclui ambas as dimensões, individuais e coletivas.

\section{PROCEDIMENTOS METODOLÓGICOS}

Essa pesquisa tem natureza qualitativa e quantitativa, o que permite aos pesquisadores explorar o que determinadas pessoas pertencentes ao contexto pensam sobre o fenômeno estudado. Assim, o enfoque qualitativo fica circunscrito ao quanto as características identificadas pelas percepções dos respondentes convergem ou divergem (BRANNEN, 2012).

A pesquisa qualitativa permite ao pesquisador desenvolver detalhes da pesquisa e estar envolvido nas experiências dos participantes, permitindo a interpretação de dados para realizar a descrição de cenários. Já na pesquisa quantitativa, o pesquisador usa questões e hipóteses para moldar seu objeto de estudo, verificando a frequência de um determinado fenômeno social (CRESWELL, 2007).

O estudo de um único caso foi escolhido pela singularidade do caso e por permitir que seja feita uma análise mais aprofundada (YIN, 2004). Em sua operacionalização, se fez uso de um protocolo de pesquisa, trata-se de um documento com todos os passos a serem realizados na pesquisa e usado para orientar a realização do estudo de forma lógica, aprofundada e eficiente (FONTENELLES, SIMÕES, FARIAS e FONTENELLES, 2009). É 
no protocolo de pesquisa que é feita a transcrição científica à pergunta formulada pelo pesquisador (LUNA FILHO, 1998).

A coleta de dados deu-se com uma entrevista com roteiro semi- estruturado. O registro das respostas foi feito por gravação de áudio e com uso de termo de confidencialidade (GIL, 2002). O tempo de entrevista foi de duas horas e meia e toda a gravação foi transcrita e validada pelo entrevistado. O conteúdo da entrevista baseou-se nos seguintes questionamentos:

- Qual a trajetória profissional do fundador da organização?

- Quais os valores pessoais que ele não abre mão de tê-los na organização?

- Qual é a visão dele sobre o papel da área de recursos humanos?

- Como ele enxerga a organização após a realização do processo sucessório?

- Como o fundador elabora e compartilha a estratégia de negócio dentro da organização?

Para a pesquisa de natureza quantitativa, foi sistematizado um questionário com perguntas fechadas e derivadas do posicionamento do fundador sobre o tema pesquisado, para os níveis gerencial e operacional da organização estudada, além dos conteúdos oriundos do referencial bibliográfico. O questionário foi composto por 48 questões, abrangeu os seguintes tópicos: como é tratado o tema estratégia de negócio na organização e qual é o papel atual da área de recursos humanos na empresa. Utilizou-se a escala likert de concordância (1- discordo totalmente e 5- concordo totalmente).

Participaram da pesquisa, 24 funcionários que ocupavam diversos cargos na organização, realizada na primeira quinzena de fevereiro de 2015. Os dados coletados nesta fase da pesquisa foram trabalhados com análise estatística descritiva.

\section{O CASO: EMPRESA DE SOLUÇÕES INTEGRADAS DE LOGÍSTICAS DE SUPER PESADOS}


Optou-se por estudar a empresa objeto de estudo pelo destaque que a mesma possui dentro do mercado de soluções integradas de logísticas e movimentação de cargas super pesadas. Em 2016 foi eleita pela revista especializada inglesa International Cranes and Specialized Transport a $37^{\text {a }}$ (trigésima sétima) maior empresa do mundo no seguimento, dentre 50 (cinquenta) listadas, e a $1^{\text {a }}$ (primeira) da América Latina especializada em transporte de cargas indivisíveis e super pesadas com peso acima de 100 toneladas, isto é, transportes realizados através de reboques modulares hidráulicos, de acordo com o Ranking ICTRANSPORT 50 (FONTE: SITE).

Nos últimos cinco anos tem vencido consecutivamente o prêmio de "Transporte Especial" como o case do ano, que tem por objetivo eleger as melhores empresas nacionais de transporte de cargas pesadas e indivisíveis.

\subsection{A carreira do fundador versus a origem da empresa}

H.Z. iniciou sua trajetória profissional aos 18 anos, quando ingressou na FEI e com 22 anos comprou uma participação de um sócio do seu pai, que estava se retirando de um acordo de sócios. Nesse momento, o fundador já se posicionava com uma visão estratégica de sua carreira e do futuro negócio:

No De 6 caminhões que nós tínhamos na época, sendo uma empresa totalmente dirigida ao transporte de maquinários de terraplanagem. O desafio na época, a vontade, fui "mordido por um mosquito" e tinha como o objetivo de ser líder, de ter uma empresa grande como já havia duas empresas concorrentes na época. Era uma empresa modelo da época, a Superpesa. Queria ser uma empresa igual a ela. Era na época uma situação que poderíamos dizer quase impossível pelo tamanho que era a Superpesa e pelo tamanho que nós éramos. Porém, foi meu foco. Então foi traçado e sempre fui nessa direção de ser líder. (SICHZ). ${ }^{2}$

No final da década de 80, a empresa de sua família já estava entre as três maiores do setor no Brasil. Esse crescimento se deu pela compra de concorrentes, sempre maiores do que a sua organização. De 1990 até 1998, a empresa participou dos maiores projetos de

\footnotetext{
${ }^{2}$ SIC: Segundo informações do cliente, transcrição literal da entrevista.
}

REMIPE- Revista de Micro e Pequenas Empresas e Empreendedorismo da Fatec Osasco V. 2, N², jul.-dez. 2016 
infraestrutura do país, como o gasoduto Brasil-Bolívia. Essa vertente de atuação internacional da empresa reflete uma característica pessoal do entrevistado, onde é possível perceber os valores pessoais da família presentes na estratégia da organização, conforme nota-se no trecho a seguir:

Sempre foi uma vocação, uma vontade que eu tinha, de ser do mundo. É um cacoete que eu tenho de visitar, de conhecer e apesar de não falar inglês fluentemente eu tinha amigos no mundo inteiro. Tinha contatos sempre relacionados a esse segmento de transporte e também nós tivemos na atividade da América Latina onde eu criei várias parcerias e várias alianças.

Em 1999, H.Z., que havia acabado de deixar a sociedade familiar de uma empresa do mesmo setor, decide por fundar a empresa objeto desse estudo. Ao longo dos últimos 17 anos o escopo da empresa vem se modificando, conforme Tabela 2, como forma de atender as demandas do mercado nacional e internacional.

Tabela 2. Evolução do escopo de negócio da organização estudada desde a sua fundação

\begin{tabular}{|c|c|c|}
\hline ANO & $\begin{array}{l}\text { ESCOPO DE } \\
\text { NEGÓCIO }\end{array}$ & DESCRIÇÃO DA ATUAÇÃO DA ORGANZIÇÃO \\
\hline 1999 & FreightForwarder & $\begin{array}{l}\text { Sem frota própria e foco no mercado internacional, com } \\
\text { baixo custo e alta rentabilidade }\end{array}$ \\
\hline 2003 & $\begin{array}{l}\text { Transporte } \\
\text { rodoviário de } \\
\text { superpesados }\end{array}$ & $\begin{array}{l}\text { Passa a realizar transporte rodoviários nacionais, } \\
\text { aproveitando o crescimento da economia e expansão da } \\
\text { indústria de base brasileira }\end{array}$ \\
\hline 2008 & $\begin{array}{l}\text { Movimentação de } \\
\text { cargas especiais }\end{array}$ & $\begin{array}{l}\text { Desenvolvimento e aquisição de equipamentos de } \\
\text { tecnologia de ponta importados, além de criação da área } \\
\text { de engenharia, o que permitiu atuar no mercado } \\
\text { petrolífero que teve seu auge com o pré sal }\end{array}$ \\
\hline 2015 & $\begin{array}{l}\text { Transporte } \\
\text { rodoviário de } \\
\text { superpesados }\end{array}$ & $\begin{array}{l}\text { Aquisição de novos equipamentos transportadores, } \\
\text { ampliando a capacidade técnica de transporte rodoviário } \\
\text { e mudança no foco de negócio devido à grave crise } \\
\text { financeira que atingiu o país em } 2015 \text {. }\end{array}$ \\
\hline
\end{tabular}

Fonte: Dados da pesquisa, 2016. 


\subsection{Análise sobre a influência do fundador e a disseminação da estratégia do negócio}

Nos últimos cinco anos a empresa teve um crescimento de $65 \%$ em seu quadro de colaboradores. A presidência da empresa é ocupada por seu fundador e a diretoria é composta por dois de seus três filhos e colaboradores de longa data, que trabalham com ele desde a sua empresa familiar anterior. O presidente também é o responsável pelas áreas tidas por ele como estratégicas que são: marketing, jurídico e institucional. A atuação do fundador como o principal dirigente da organização, imprime os seus valores pessoais na base da cultura organizacional (FERREIRA et al, 2006, p.1).

A empresa atualmente tem cerca de 120 funcionários, o maior número de pessoas em seu quadro desde a sua fundação em 1999. A estrutura da empresa é composta por três grandes áreas: diretoria/gerência, administrativo e operacional e para essa pesquisa foram consideradas dois grupos: diretoria, gerência/tático e operacional, onde são contemplados também o público da área administrativa.

A partir de 2014 a empresa iniciou a implantação da cultura de planejamento estratégico, através da parceria com a Fundação Dom Cabral, com o programa Parceiros para a Excelência. Nessa reestruturação, foram analisados e redefinidos a missão, visão e valores da organização. A empresa tem como missão movimentar cargas super pesadas de forma criativa, rentável, eficiente, com ética, responsabilidade econômica, social, ambiental, superando as expectativas dos clientes, colaboradores e fornecedores (Fonte: Site).

Durante a entrevista é possível levantar alguns pontos em comum entre a missão da empresa e os valores pessoais de seu fundador, essa conexão pode ser percebida em alguns trechos da entrevista. No decorrer da entrevista, H.Z. se descreve como criativo, que segundo ele influenciou na escolha de sua formação superior, o marketing. Em outro trecho, nota-se a ênfase no relacionamento transparente e ético com seus colaboradores, quando destaca que não abre mão da ética e transparência em seus relacionamentos. Outro ponto a destacar, quando indagado sobre como conduz o seu negócio, o entrevistado diz:

Eu acho que nós temos muito bem uma definição de cultura da empresa, de qualidade, de relação com o cliente, de performar o serviço. Seriedade do negócio. Aqui não é um lugar simplesmente de buscar o lucro a qualquer custo. Nós temos uma empresa que tem um cunho social muito grande.

REMIPE- Revista de Micro e Pequenas Empresas e Empreendedorismo da Fatec Osasco V. 2, №2, jul.-dez. 2016 
As situações apontadas demonstram claramente os reflexos da história de vida e valores do fundador na cultura organizacional e na forma de gestão de seu negócio (FLEURY E FLEURY, 2007).

A empresa determinou como sua visão ser uma empresa globalizada e referência mundial por suas estratégias ousadas, criativas e inovadoras nas movimentações de cargas super pesadas. Retomando em 2015 a atuação no nicho de mercado que deu a sua fundação, a área de logística internacional especialmente voltada a América Latina, a empresa busca reforçar seu status de empresa globalizada. Essa globalização da empresa também se da pela parceria com empresas e fornecedores de fora do país, como no desenvolvimento conjunto com a Mercedez-Benz em 2014 de cavalos mecânicos voltados ao segmento de super pesados.

Como valores da empresa foram definidos valor à vida, respeito, qualidade, responsabilidade, ética e transparência nas relações com os fornecedores, colaboradores e clientes, competência, conhecimento, comprometimento, democracia no trabalho e espírito de equipe. Analisando a entrevista realizada com o fundador é possível notar alguns de seus valores pessoais, como no trecho onde fala: "Tento alcançar os resultados com foco, determinação, perseverança, muita perseverança e a satisfação quando você vê o resultado das três primeiras palavras".

No que diz respeito à estratégia de negócio, em 2014, pela necessidade de iniciar a preparação para o processo sucessório, o empresário notou a necessidade de maior disseminação da estratégia de negócio, pois se deu conta de que ficava restrita apenas a ele, como destacado no trecho a seguir:

\footnotetext{
A estratégia ficava muito concentrada em mim e eu passava conversando, informalmente. Eu não tinha nada estruturado. Eu estava muito próximo da empresa e ia tocando, orientando, procurando orientar, procurando treinar de alguma maneira, sempre atrás do objetivo que estava na minha cabeça. Eu não divulgava isso.
}

Desde então, a empresa tem uma sólida parceira com a Fundação Dom Cabral, onde a implantação da cultura do planejamento estratégico vem acontecendo agora com a participação de toda a direção, e não mais apenas dependendo exclusivamente de seu 
presidente. Em pesquisa realizada na mesma empresa em 2013, 90\% dos colaboradores desconheciam qual era a estratégia de negócio da empresa, dada a centralização que ocorre no processo de elaboração da estratégia nas empresas de pequeno e médio porte (LIMA, 2007). Dentro desse número encontravam-se também a diretoria e gerencia da organização, onde cada um tinha uma ideia diferente do que era a estratégia de negócio dessa empresa.

Um dos pilares da estratégia de negócios da empresa é ter foco, como por exemplo, manter a prestação de serviços sendo feitos pelos reboques modulares hidráulicos, mesmo quando havia demanda de mercado para outros tipos de equipamento. No entanto, o fundador reconhece que as premissas que norteiam ainda a organização são definidas através de sua experiência de vida e conhecimento adquirido, que chama de feeling, e que isso não é possível passar adiante em um processo sucessório, como citado no seguinte trecho da entrevista:

E essa é a questão do fundador. Ele tem uma característica, uma peculiaridade que às vezes o faz ter sucesso. Ele cresce a empresa, com todas as informalidades, com uma maneira própria. Essa maneira, esse feeling, isso você não transfere ao teu sucessor por mais que você queira. E cada pessoa tem um jeito de administrar.

Outra vertente apontada como estratégia da empresa é o conhecimento técnico do negócio e conhecimento de mercado de seu principal dirigente, que dá agilidade na mudança da rota empresarial antes de seus concorrentes. Conhecendo bem seu negócio, de acordo com o entrevistado, é possível corrigir as falhas internas e aumentar a produtividade, num setor onde não existe preocupação com performance de alto nível. Além disso, a visão de mercado permite atuar em áreas inexploradas pelos concorrentes, dando pioneirismo na atuação de certos mercados, como com a formação da área de engenharia que permitiu forte atuação no setor de Oil\&Gas de 2008 até 2014.

Com a parceria da Fundação Dom Cabral, os objetivos estratégicos da empresa são compartilhados com todos os níveis da organização através de planos de ação que envolvem diversos grupos de colaboradores, e a empresa passou a contar com uma série de indicadores além dos financeiros, como os de performance comercial e operacional. Esses indicadores passaram a nortear as ações de todos os departamentos para alcançar o sucesso dos objetivos estratégicos da organização. 


\subsection{Análise sobre a influência do fundador e a disseminação da estratégia de gestão de pessoas}

Desde a criação da área de recursos humanos, o presidente ressalta que a área burocrática da gestão de pessoas, ou seja, o departamento pessoal, seja totalmente separado dos recursos humanos. No organograma são áreas distintas e com gestores distintos, sendo o departamento pessoal parte do departamento financeiro.

Durante a implantação do planejamento estratégico, a diretoria, com exceção do presidente, observou que um dos grandes problemas dentro da organização era a falta de gestão de pessoas, tendo em vista que o departamento de RH fora extinto pelo fundador, já que, na visão dele, por ser um ano de crise, em 2015 a empresa não contrataria novos colaboradores e não havia necessidade de ter essa área na empresa. Após estudos realizados pela diretoria e diversas reuniões com a Fundação Dom Cabral, o presidente decidiu implantar novamente a área de RH, dessa vez com o foco verdadeiramente estratégico. A área dessa vez ficaria subordinada ao vice-presidente e não mais ao fundador e trabalharia diretamente na elaboração e implantação dos objetivos estratégicos da organização.

Nesse cenário, mais uma vez fica evidente a influência do fundador dentro da organização, pois apenas quando ele julgou necessário é que foi implantado novamente o departamento de RH na empresa. Lourenço e Ferreira (2012) apontam que o fundador tem o poder de desenvolver a cultura da organização, baseado em seus valores e suas crenças, sendo âncoras que apoiam toda a estrutura. Quanto à atuação estratégica de RH, deixa de reagir aos fatos se antecipando a eles e deixa de ser visto como um centro de custo e passa a ser visto como agregador de valor ao negócio (BOXALL, 1996).

A empresa traz como um dos princípios gerenciais "Estimular o intercâmbio de conhecimento, o desenvolvimento e a realização profissional de seus colaboradores" (Fonte:Site). Nota-se que isso reflete um valor pessoal do fundador de sobre a importância da área de recursos humanos para a organização.

Sempre me dediquei ao RH, minha vida inteira. Isso é muito importante pra mim, um apoio direto a administração da empresa o departamento de recursos humanos. A contratação tem que estar muito bem afinada pra que ela me dê os elementos humanos para que eu implemente a minha estratégia. Ela tem que me conhecer para

REMIPE- Revista de Micro e Pequenas Empresas e Empreendedorismo da Fatec Osasco V. 2, №2, jul.-dez. 2016 
saber quais as ferramentas humanas que eu preciso para que eu consiga o resultado da estratégia.

Em estudo realizado em 2013, observou-se que a organização era considerada estratégica pela direção, mas nessa época ser estratégico para o RH era o processo de recrutamento e seleção apenas, conforme nota-se na visão do presidente na entrevista realizada em 2016. Após 2014, com o trabalho desenvolvido sobre PE, percebeu-se que a área poderia auxiliar a empresa estrategicamente participando da elaboração dos objetivos estratégicos e tendo suas políticas baseadas na estratégia de negócio (BREWSTER, 1994). Em 2016, a gestora de RH passou a ser um membro do comitê estratégico da empresa, ao lado da diretoria e gerência da empresa.

É possível notar que a cultura dessa organização difere das empresas com características iguais as suas, de gestão familiar e de pequeno porte, onde o RH é visto como um centro de custos e de perfil burocrático (RAVAGLIA, 2012). Lacombe e Tonelli (2001) retratam que o papel estratégico do $\mathrm{RH}$ precisa integrar as variantes do ambiente, as necessidades advindas dos objetivos organizacionais em longo prazo e a necessidade no que tange às pessoas.

Ainda no âmbito sobre sua relação com seus colaboradores, H. Z. salienta que preza pela transparência e respeito nos relacionamentos com seus colaboradores. Uma das premissas que não abre mão na gestão de seu negócio é o pagamento dos funcionários "religiosamente em dia" como ele destacou bem durante a entrevista. Apontou também que sua empresa não é o tipo de empresa que visa o lucro acima de tudo, e por isso possui um cunho social muito grande.

Tem as pessoas que são nossos empregados, tem nossos clientes e logicamente eu tenho que buscar o lucro, mas também busco esse crescimento que nós temos, uma sustentabilidade, perpetuar a empresa pelo menos pelo tempo que eu possa estar presente e não um negócio só para fazer dinheiro. Assim como eu, meus funcionários buscam a ascensão social, proporcionar melhoria no nível de vida a sua família e que quero ajudá-los a fazer isso.

Ideologia típica de empresa familiar, segundo Franco e Haase (2012) onde a cultura corporativa é baseada na lealdade, gratidão e cooperação entre as partes para atingir o sucesso da organização. Para Barreto (2003) o fundador através da sua história de vida e seus valores, 
estabelece as premissas da organização e de seu papel de líder. Nesse caso, é possível observar em como a influência do fundador molda os valores e comportamentos organizacionais sobre a gestão de pessoas.

\section{CONCLUSÃO}

Por meio desse estudo de caso foi possível constatar que nas empresas de gestão familiar existem diferenças em como a estratégia de negócio e como a estratégia de recursos humanos são disseminadas para a organização, ambas exercendo influência direta de seu fundador.

No caso da estratégia de negócio, durante 15 dos 17 anos de existência da empresa, o fundador não compartilhou e nem disseminou a estratégia de negócio, pelos mais diversos motivos, como o tamanho que a empresa tinha e por receio que a estratégia fosse descoberta pela concorrência, em um mercado onde existem poucos players, uma vez que a abertura desse tipo de negócio exige um intenso capital inicial.

Já sua estratégia de recursos humanos sempre foi divulgada e reforçada junto aos seus colaboradores e mercado, já que é um diferencial nesse seguimento, especialmente a importância e respeito dados às relações empresa x colaborador.

Conclui-se dessa forma que, para o fundador, mesmo que ele não tenha consciência total do papel da gestão estratégica de pessoas, ele a pratica, uma vez que seus valores e seu nível de relacionamento com seus funcionários tornam-se uma de suas prioridades desde o início de seu negócio. Já a estratégia de negócio, dada a sua complexidade e seu impacto na organização no âmbito interno e externo, o fundador tende a centralizar e não disseminar a estratégia para toda a organização.

\section{REFERÊNCIAS}

Barbosa, J. D., \& Teixeira, R. M. (2003). Gestão estratégica nas empresas de pequeno e médio porte. 
Barreto, E. (2003). Estilos gerenciais e o impacto das organizações. Tese (Doutorado em Administração) -Universidade Federal da Bahia, Salvador.

Boxall, P. (1996). The strategic HRM and debate the resource-based view of the firm. Human Resource Management Journal. 6(3), 59-75.

Boxall, P., \& Purcell, J. (2011). Strategy and human resource management. Palgrave Macmillan.

Brandão, H. P., ZIMMER, M. V., Pereira, C., Marques, F., Costa, H., Carbone, P. P., \& Almada, V. (2008). Gestão de desempenho por competências: integrando a avaliação 360 graus, o balancedscorecard e a gestão por competências. Revista de Administração Pública, 42(5), 875-98.

Brannen J. (2012) Mixing Methods: The Entry of Qualitative and Quantitative Approaches into the Research Process. International Journal of Social Research Methodology.

Brewster, C., \& Hegewisch, A. (Eds.). (1994). Policy and Practice in European Human Resource Management: The Price Waterhouse Cranfield Survey. Routledge.

Casillas, J. C., Vázquez, A., \& Díaz, C. (2007). Gestão da empresa familiar: conceitos, casos e soluções. São Paulo: Thomson.

Change Integration da Price Waterhouse (1999). Princípios e Paradoxos. Atlas.

Contador, J. C. (1995). Recomendações sobre o processo de planejamento estratégico. Revista de Administração de Empresas, 35(3), 39-48.

Costa, L. M. D. S. S., \& Barbosa, J. G. P. A Cultura Organizacional e Seus Impactos na Formação das Estratégias Empresariais.

Creswell, J.W. (2007). Projeto de pesquisa: método qualitativo, quantitativo e misto. Porto Alegre: Artmed.

Ferreira, J. F.; Teixeira, M. L. M. (2006). Papéis de Recursos Humanos: uma visão ampliada pelas ações e expectativas percebidas. Sociedade, Contabilidade e Gestão, 1 (1), 58-73.

Fontelles, M. J., Simões, M. G., Farias, S. H., \& Fontelles, R. G. S. (2009). Metodologia da pesquisa científica: diretrizes para a elaboração de um protocolo de pesquisa. Revista Paraense de Medicina, 23(3), 1-8.

Franco, M. e Haase, H. (2012). A comparative study of cooperative relationships in family and non-family businesses. African Journal of Business Management, 6(44), 10873-10887.

Freitas, E. C., \& Barth, M. (2012). De pai para filho: a complexidade e os desafios da gestão das empresas familiares. Revista de Administração da UFSM, 5(3), 549-568.

Fleury, A., \& Fleury, M. (1997). Aprendizagem e cultura nas organizações. Aprendizagem e inovação organizacional: as experiências de Japão, Coréia e Brasil. São Paulo: Atlas. 
Freitas, M. E. (1991). Cultura organizacional: formação, tipologias e impacto. Makron.

Freitas, A. D. (1997). Traços brasileiros para uma análise organizacional. Cultura organizacional e cultura brasileira. São Paulo: Atlas, 38-54.

Gil, A. C. (2002). Como elaborar projetos de pesquisa. São Paulo, 4.

Holanda, A. (2012). Questões sobre pesquisa qualitativa e pesquisa fenomenológica. Análise psicológica, 24(3), 363-372.

Huallem, D. (2011). A importância do RH nas PMEs. Revista Você S/A. Recuperado de http://revistavocerh.abril.com.br/materia/a-importancia-do-rh-nas-pmes.

Kaplan, R. S., \& Norton, D. P. (2000). Organização orientada para a estratégia: como as empresas que adotam o balancedscorecard prosperam no novo ambiente de negócios. Gulf Professional Publishing.

Lacombe, B. M. B., \& Tonelli, M. J. (2001). O discurso e a prática: o que nos dizem os especialistas e o que nos mostram as práticas das empresas sobre os modelos de gestão de recursos humanos. Revista de administração contemporânea, 5(2), 157-174.

Lethbridge, E. (1997). Tendências da empresa familiar no mundo. Revista do BNDES, 7(1).

Lévy, A. (2013). Conjunção, na empresa, de um projeto pessoal e familiar, com a história de uma região: o processo de criação institucional. Psicossociologia: Análise social $e$ intervenção.

Lima, E. (2007). Visão compartilhada, equipe de direção e gestão estratégica de pequenas e médias empresas: um estudo multi-caso e internacional. Revista de Negócios, 12(4), 86-100.

Lima, E. (2010). Estratégia de pequenas e médias empresas: uma revisão. REGE Revista de Gestão, 17(2), 169-187.

Lucas, M. F. C. (2013). A Gestão Familiar de PME (Doctoral dissertation, Universidade de Beira Interior).

Lucas, M., \& Franco, M. (2014). Influências e particularidades na gestão familiar de PME: uma abordagem qualitativa.Revista de Estudios Económicos y Empresariales, 26, 39-73.

Luna, F. (1998). Sequiência básica na elaboração de protocolos de pesquisa. Arquivos brasileiros de cardiologia, 71(6), 735-740.

Mayson, S.; Barrett, R. (2006) The 'science' and 'pratice' of HRM in small firms. Human Resource Management Review, 16, 447-455.

Mintzberg, H.; Ahlstrand, B.; Lampel, J. (2000). Safári de estratégia: um roteiro pela selva do planejamento estratégico. Porto Alegre: Bookman. 
Lourenço, C. D. S., \& Ferreira, P. A. (2012). Cultura Organizacional e Mito Fundador: Um Estudo de Caso em uma Empresa Familiar. Gestão \& Regionalidade (Online), 28(84).

Papa, A. C., \& Luz, T. R. (2008). O papel do fundador na cultura de uma empresa familiar: um estudo de caso em João Monlevade-MG. Anais do Encontro da Associação Nacional de Pós-Graduação em Pesquisa e Administração.

Penrose, E. (1959). The theory of the growth of the firm.

Pereira, M. F., \& Agapito, F. (2007). Afinal, como se forma as estratégias?. Revista de Administração FACES Journal, 6(3).

Porter, M. E. (1980). Competitive analysis.

Prahalad, C., \& Hamel, G. (1998). A Competência Essencial da Corporação In: Estratégia-a busca da vantagem competitiva. Rio de Janeiro: Campus.

Ravaglia, G de N.P. (2012). Modelos de gestão de pessoas em empresas de médio porte: um estudo de multicascos no ramo varejista de utilidades para o lar no estado do Rio de Janeiro (Trabalho de conclusão de curso - Fundação Instituto de Administração).

Shein, E. H. (1992). Psicologia organizacional. Prentice-Hall.

Silva, S. J., Fernandes, A. T., \& Escrivão Filho, E. (2009). Planejamento estratégico e operacional na pequena empresa: um estudo sobre a sua influência no desempenho dos empreendimentos do setor de base tecnológica de São Carlos/SP. Revista de Negócios, 14(1), $29-45$.

Silveira, V. N. S., \& Del Maestro Filho, A. (2013). Gestão Estratégica de Pessoas E Desempenho Organizacional-Uma Análise Teórica. Revista Pretexto, 14(1), 71-87.

Storey, J. (2007).Human resource management: A critical text. Cengage Learning EMEA.

Teixeira, D. L. P. (1984). A estrutura de poder, o paternalismo e o papel da assessoria técnica gerencial na pequena empresa industrial. Revista de Administração de Empresas, 24(2), 13 17.

Tracey, J. B., \& Nathan, A. E. (2002). The strategic and operational roles of human resources an emerging model.The Cornell Hotel andRestaurantAdministrationQuarterly, 43(4), 17-26.

Ulrich, D. (2006) Os campeões de RH: Inovando para obter os melhores resultados. 15-73.

Yin, R.K. (2001) Estudo de caso: planejamento e métodos.

Z.H. Entrevista I. (fev.2016). Entrevistador: Juliana Popp Barbosa Lima. Guarulhos 


\section{APÊNDICE}

\section{Roteiro da entrevista.}

1. Como foi a sua trajetória comercial desde o início até os dias atuais?

2. Quais são os princípios profissionais que você não abre mão?

3. Quando você tem dificuldades, por exemplo, quando você saiu da empresa anterior, como você superou?

4. Na sua atual empresa, como você mantém o foco da empresa? Como você classifica seu estilo de gestão?

5. Dos seus valores pessoais, como você acredita que os passa aos seus colaboradores?

6. Quais os valores que você admira em seus funcionários?

7. Antes de haver o planejamento estratégico, como você passava a estratégia para a sua diretoria?

8. Como você enxerga a empresa e sua relação com ela a longo prazo? Já pensou no processo de sucessão?

9. Quando você fundou a sua atual empresa, você a fez pensando na sua família. Mas se no futuro, seus filhos não estiverem na direção, como você lidaria com isso?

10. As decisões estratégicas, você as compartilha com alguém?

11. Como você enxerga que o RH vai te ajudar, como fundador, a implementar a estratégia de negócio dentro da empresa?

12. Você acredita que quando você se afastar da empresa, seus valores irão permanecer? 